\title{
Seasonal variability in irradiance affects herbicide toxicity to the marine flagellate Dunaliella tertiolecta
}

\author{
Sascha B. Sjollema ${ }^{1}{ }^{*}$, Charlotte D. Vavourakis ${ }^{1}$, Harm G. van der Geest ${ }^{1}$, A. Dick Vethaak ${ }^{2,3}$ and \\ Wim Admiraal ${ }^{1}$ \\ 1 Department of Aquatic Ecology and Ecotoxicology, Institute for Biodiversity and Ecosystem Dynamics, University of Amsterdam, Amsterdam, Netherlands \\ 2 Deltares, Marine and Coastal Systems, Delft, Netherlands \\ ${ }^{3}$ Department Chemistry and Biology, Institute for Environmental Studies (IVM), VU University Amsterdam, Amsterdam, Netherlands
}

Edited by:

Ram Kumar, Central University of

Bihar, India

\section{Reviewed by:}

Xiaoshou Liu, Ocean University of China, China

Dongyan Liu, Chinese Academy of Sciences, China

\section{*Correspondence:}

Sascha B. Sjollema, Department of Aquatic Ecology and Ecotoxicology, Institute for Biodiversity and

Ecosystem Dynamics, University of Amsterdam, Science Park 904, 1098 XH Amsterdam, Netherlands e-mail: s.b.sjollema@uva.nl
Photosynthetically Active Radiation (PAR) and Ultraviolet Radiation (UVR) of the solar spectrum affect microalgae directly and modify the toxicity of phytotoxic compounds present in water. As a consequence seasonal variable PAR and UVR levels are likely to modulate the toxic pressure of contaminants in the field. Therefore, the present study aimed to determine the toxicity of two model contaminants, the herbicides diuron and Irgarol ${ }^{\circledR} 1051$, under simulated irradiance conditions mimicking different seasons. Irradiance conditions of spring and autumn were simulated with a set of Light Emitting Diodes (LEDs). Toxicity of both herbicides was measured individually and in a mixture by determining the inhibition of photosystem II efficiency (ФPSII) of the marine flagellate Dunaliella teriolecta using Pulse Amplitude Modulation (PAM) fluorometry. Toxicity of the single herbicides was higher under simulated spring irradiance than under autumn irradiance and this effect was also observed for a mixture of the herbicides. This irradiance dependent toxicity indicates that herbicide toxicity in the field is seasonally variable. Consequently toxicity tests under standard light conditions may overestimate or underestimate the toxic effect of phytotoxic compounds

Keywords: seasonal variability, irradiance, herbicide toxicity, microalgae, pulse amplitude modulation (PAM) fluorometry

\section{INTRODUCTION}

Microalgae are primary producers and play a key role in aquatic ecosystems due to their position at the base of food webs. Hence, toxicants affecting microalgae potentially affect the carrying capacity of marine and freshwater ecosystems (Hylland and Vethaak, 2011). Herbicides are, due to their specific mode of action, amongst the most harmful contaminants for microalgae. Because herbicides act often directly on the photosynthetic machinery, solar radiation is likely a key factor determining the actual toxicity of herbicides in the field. Numerous studies investigated the effect of light stress on individual microalgal species as well as on natural phytoplankton communities (Vassiliev et al., 1994; Buma et al., 2001; Helbling et al., 2001). Photosynthetically Active Radiation (PAR, 400-700 nm) is captured by the light harvesting pigments in the chloroplasts of the microalgae and is used to convert $\mathrm{CO}_{2}$ and water into carbohydrates during photosynthesis. PAR will be a limiting factor for algal photosynthesis when radiation is low, while excess radiation causes oxidative stress reducing the photosynthetic capacity (Kirk, 2011). Simultaneously, microalgae are exposed to Ultra Violet Radiation (UVR, $<400 \mathrm{~nm}$ ) which has the potential to damage important biochemical molecules (Larson and Berenbaum, 1988). Excess radiance levels of PAR and UVR may result in the formation of Reactive Oxygen Species (ROS) which may lead to a decreased photosynthetic efficiency or even viability loss (Janknegt et al., 2009a). At the same time, light may also affect compound toxicity in several ways. Solar radiation, especially UVR, may cause degradation of the contaminant, creating transformation products with a potential different persistence and modified toxicity to microalgae. Additionally, UVR can change the structure of a compound through photomodification or photosensitization which may enhance toxicity, a phenomenon known as photo-enhanced toxicity, described for PAHs (Gala and Giesy, 1992; Wiegman et al., 2001; Southerland and Lewitus, 2004), PCBs (Ruben et al., 1990), TBT (Sargian et al., 2005) as well as pesticides (Guasch and Sabater, 1998; Lin et al., 1999; Pelletier et al., 2006). Considering the described direct and indirect effects of solar radiation on microalgae and contaminants and the fact that intensity of PAR and UVR vary strongly over the year, it is likely that solar irradiance might play an important role in the ultimate toxicity in the field. Consequently, it can be expected that standard toxicity tests may over- or underestimate toxicity of contaminants when compared to the actual toxicity under variable field conditions.

Nevertheless, there has been little attention paid toward seasonal variation in toxicity. Guasch et al. (1997) described a difference in herbicide toxicity between seasons for natural periphyton communities, but as several environmental factors were tested together, it is unclear if the observed difference was caused by a seasonal difference in light conditions. Yet, experimental confirmation on the effect of seasonal variability in solar irradiance on herbicide toxicity is still lacking. Therefore, we aimed to determine herbicide toxicity to microalgae under simulated irradiance conditions mimicking different seasons. Of the total solar radiation $100 \%$ of the UVC and $90 \%$ of the UVB radiation 
is blocked by stratospheric ozone, while UVA $(320-400 \mathrm{~nm})$ is hardly retained (Coldiron, 1992). As a consequence, microalgae in the water are mainly exposed to UVA $(315-400 \mathrm{~nm})$ and PAR (400-700 nm). Additionally, it has been demonstrated that photosynthesis of a natural phytoplankton community is more inhibited by UVA than by UVB (Helbling et al., 2001). Consequently, the present study focuses on the effect of UVA and PAR on herbicide toxicity. Subsurface irradiance at our latitude was simulated in a laboratory setup with Light Emitting Diodes (LEDs) of different wavelengths. We selected two model herbicides, diuron and Irgarol ${ }^{\circledR} 1051$ (Cybutryne), which are both described as priority substances under the European Water Framework Directive (2013/39/EU). Toxicity tests (with both single compounds and with a mixture of both) were performed using PAM fluorometry under the mimicked light conditions to determine the effect of different seasonal light conditions on herbicide toxicity.

\section{MATERIALS AND METHODS \\ SIMULATING SOLAR RADIATION}

Light regimes were simulated in a controlled laboratory setup based on the average light intensity in spring and autumn in The Netherlands. To this purpose, the average light intensity in spring (21 March-21 June 2002-2008) and autumn (21 September-21 December 2002-2008) was obtained from the Royal Netherlands Meteorological Institute resulting in an average intensity of 202 and $53 \mathrm{~W} / \mathrm{m}^{2}$ for spring and autumn, respectively. The average daily light periods were 14:57 h:min and 9:34 h:min, respectively (Royal Netherlands Meteorological Institute). In addition, the solar spectrum was measured outside (Amsterdam, The Netherlands) at the end of May during clear sky with a USB4000 Fiber Optic Spectrometer (Ocean Optics, Dunedin, Florida, USA). This spectrum was normalized to the average calculated PAR intensities of 202 and $53 \mathrm{~W} / \mathrm{m}^{2}$ to obtain a spring and autumn light profile. Since phytoplankton is not exposed to the irradiance levels at the surface, the experimental irradiance levels were attenuated to $10 \%$ to simulate subsurface irradiance. The attenuation level was chosen to match the conditions at our field sites in the coastal zone of the North Sea with a mixed water column of ca. $30 \mathrm{~m}$ and a light attenuation co-efficient Kd of roughly $0.6 \mathrm{~m}-1$ (Delft3D-GEM for the North Sea). The 10\% irradiance level of the normalized spectrum (Figure 1, solid lines), was simulated in the laboratory with five LEDs emitting light peaking at wavelengths of $450,475,522,632$, and $685 \mathrm{~nm}$, corresponding to the absorbance maximum of the main algal pigments. An additional LED with a peak at $370 \mathrm{~nm}$ was used to simulate UVA. A total of 16 clusters of six LEDs provided homogeneous light during the experiments. The spectra for both spring and autumn light conditions, hereafter referred to as SPRING and AUTUMN, are depicted in Figure 1 (dashed lines).

\section{TEST SPECIES AND CHEMICALS}

All tests were performed with the marine flagellate Dunaliella tertiolecta (Butcher, CCAP 19/27) which was cultured in Erlenmeyer flasks on artificial seawater medium. Artificial seawater (33\%) was obtained by dissolving sea salts (Aqua Bio Solutions, Wormerveer, The Netherlands) in de-ionized water (MilliQ) and this was enriched with f/2 medium (Guillard, 1975) (Sigma Aldrich Chemie B.V., Zwijndrecht, The Netherlands). Toxicity tests were performed using diuron (CAS: 330-54-4, analytic standard, Sigma Aldrich, Zwijndrecht, The Netherlands) and Irgarol ${ }^{\circledR} 1051$ (CAS: 28159-98-0, >97\%, Ciba Specialty Chemicals Inc., Basle, Switzerland). Stock solutions of both compounds were made in methanol (ULC/MS grade, Biosolve, Valkenswaard, The Netherlands). All presented concentrations are nominal concentrations. Culturing and toxicity experiments were performed under SPRING and AUTUMN light conditions at a constant temperature of $13 \pm 0.5^{\circ} \mathrm{C}$.

\section{TOXICITY TEST}

To investigate the algal growth rate under the different irradiance regimes, cell densities of acclimatized D. tertiolecta were counted daily in a Bürker counting chamber. These data were used to

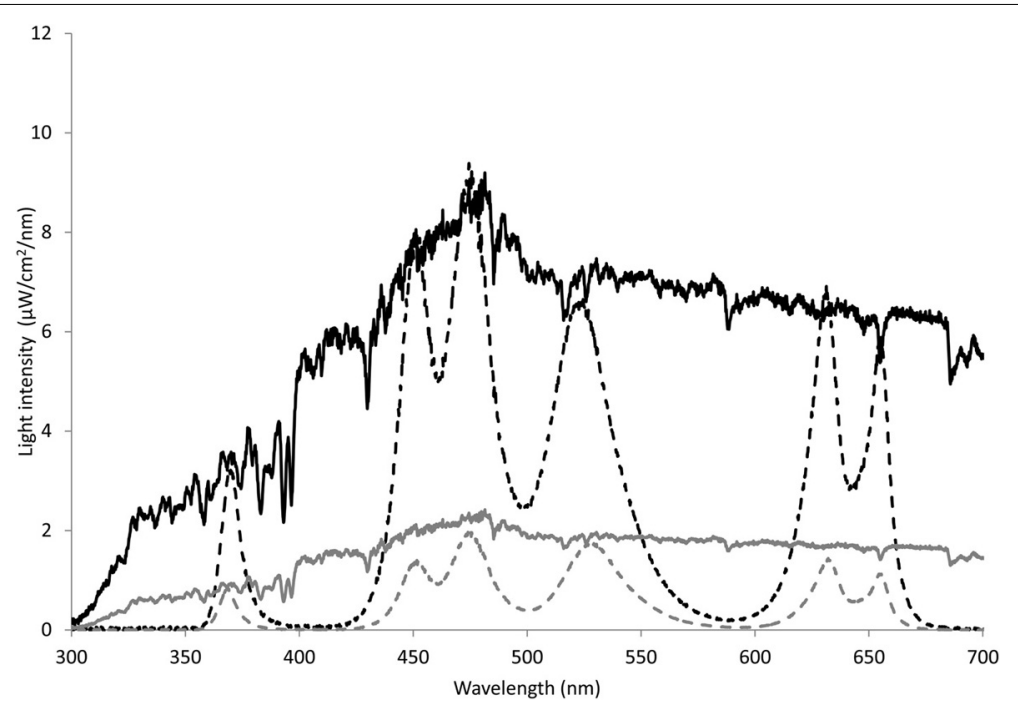

FIGURE 1 | Measured solar radiation (10\%) and simulated light regime under spring and autumn light conditions. Light intenstity $\left(\mu \mathrm{W} / \mathrm{cm}^{2} / \mathrm{nm}\right)$ of the LEDs for SPRING (black dotted line) and AUTUMN (gray dotted line) were normalized to $10 \%$ of the average solar radiation (black and gray line, respectively). 
determine the exponential growth phase under both light regimes and all toxicity experiments were performed with light adapted, exponentially growing populations. The growth rates of $D$. tertiolecta, determined by linear regression of ln-transformed cell densities were 0.8 and $0.3\left(\right.$ day $\left.^{-1}\right)$ for SPRING and AUTUMN, respectively.

The toxic effects of the $\operatorname{Irgarol}{ }^{\circledR} 1051$ and diuron (five concentrations per herbicide, six replicates per concentration and five replicates for the control) on the photosynthetic efficiency of the algae was determined for SPRING and AUTUMN. To this purpose, Pulse Amplitude Modulation (PAM) fluorometry bioassays were performed in which the effective photosystem II efficiency (ФPSII) was determined after $4.5 \mathrm{~h}$ using a WATER-PAM (Heinz Walz GmbH, Effeltrich, Germany). Minimum and maximum fluorescence ( $F$ and $F_{\mathrm{m}}^{\prime}$, respectively) were determined and ФPSII was calculated as $\left[F_{\mathrm{m}}^{\prime}-F\right] / F_{\mathrm{m}}^{\prime}$. The PSII inhibition was expressed as percentage of the corresponding solvent control (\% of control). The effect on the photosynthetic efficiency of the algae was expressed as the $50 \%$ effect concentration $\left(\mathrm{EC}_{50}\right)$. Next to the experiments with diuron and Irgarol individually, toxic effect of both herbicides was determined in a mixture for SPRING as well as AUTUMN. The Toxic Unit (TU) concept was applied for the composition of an equitoxic mixture of both herbicides, based on the individual $\mathrm{EC}_{50}$ values. The toxicity of this mixture (tested for eight concentrations) was determined using the same bioassay as described above and the results were interpreted according to the Concentration Addition model (Könemann, 1981).

The actinic light used to determine $\Phi$ PSII of these PAM measurements consisted of LEDs of $632 \mathrm{~nm}$ (chlorophyll $a$ fluorescence) which were identical to the $632 \mathrm{~nm}$ LEDs used to simulate solar radiation. The same light intensity of these LEDs was used during exposure and measurement to maintain the required simulated field relevant irradiance.

\section{DATA ANALYSIS}

The log-logistic dose-response model described by Haanstra et al. (1985) was used to determine the $50 \%$ reduction $\left(\mathrm{EC}_{50}\right)$ in $\Phi$ PSII and was calculated as $y=c /\left(1+e^{b(\log (x)-\log (a))}\right)$, where $\mathrm{y}$ is the ФPSII (\% control), $x$ is the concentration of the toxicant $(\mu \mathrm{g} / \mathrm{L})$, $a$ is the EC50 value ( $\mu \mathrm{g} / \mathrm{L}), b$ is the slope of the curve, and $c$ is the $\Phi P S I I$ of the control. Likelihood ratio tests were applied to compare effect concentrations of SPRING and AUTUMN $\left(\chi_{1}^{2}>3.84\right.$, $d f=1, p<0.05)$. The analyses were all performed with SPSS (IBM SPSS Statistics 20).

\section{RESULTS}

Clear dose-response relationships of the effect of Irgarol and diuron on $\Phi$ PSII of $D$. tertiolecta were obtained for SPRING and AUTUMN (Figure 2). The observed toxicity was significantly $(p<0.05)$ higher for SPRING $\left(\mathrm{EC}_{50}: 0.8\right.$ and $\left.3.6 \mu \mathrm{g} / \mathrm{L}\right)$ compared to AUTUMN (EC $\mathrm{E}_{50}: 1.3$ and $\left.4.8 \mu \mathrm{g} / \mathrm{L}\right)$ for Irgarol and diuron, respectively. The same pattern, with herbicides having a higher toxic effect in SPRING compared to AUTUMN, was observed for the binary mixture of the herbicides (Figure 3 ). The $\mathrm{EC}_{50}$ of the equitoxic mixture for SPRING was significantly lower $(0.8 \mathrm{TU}$, 95\% C.I. 0.7-0.9) than 1 TU, indicating a more than additive effect for the mixture of both herbicides. In contrast, the $\mathrm{EC}_{50}$ of the mixture for AUTUMN was significantly higher (1.2 TU,

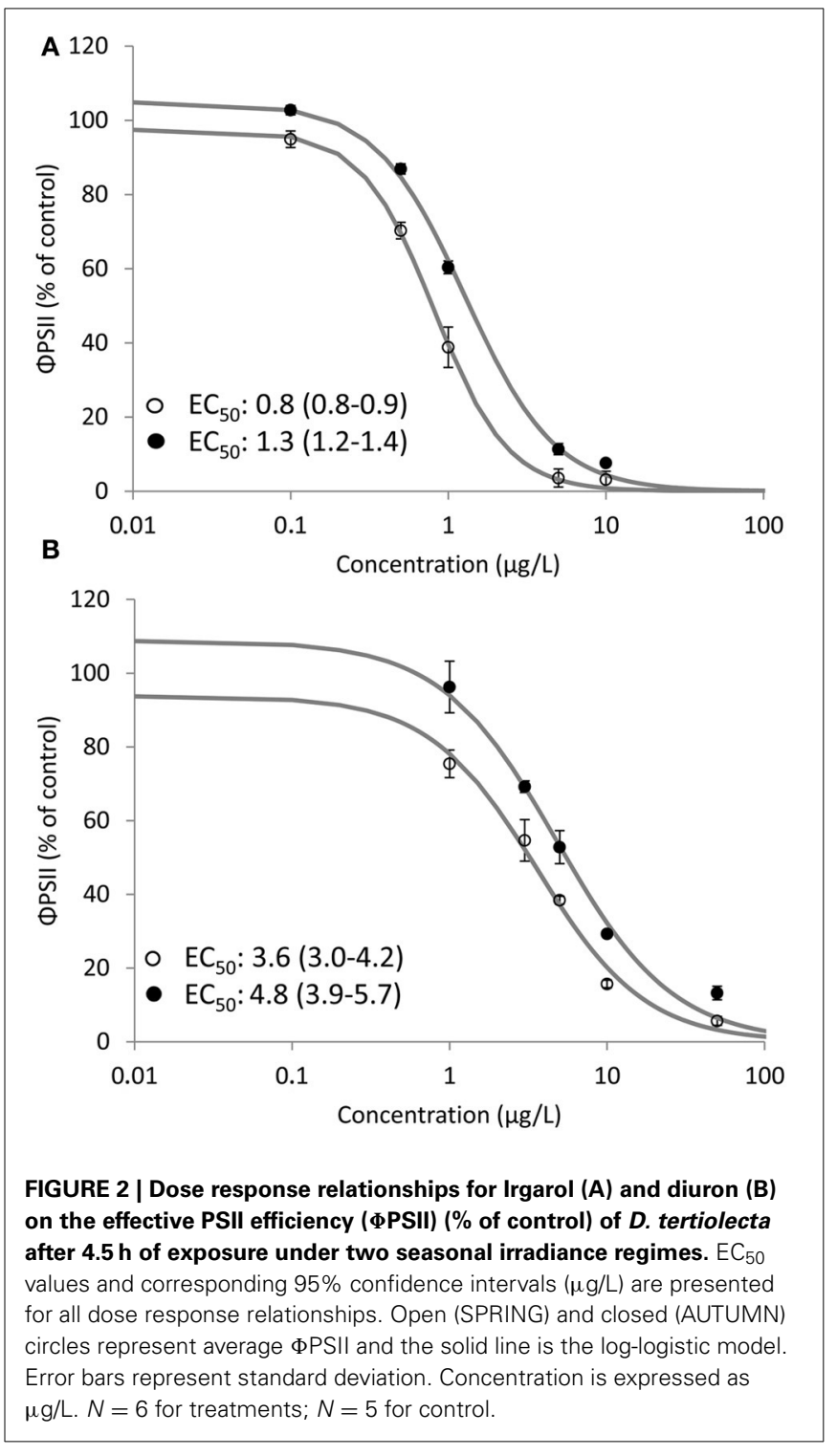

95\% C.I. 1.1-1.3) than 1 TU, indicating a less than additive effect.

\section{DISCUSSION}

We clearly demonstrated a significant difference in the toxicity of Irgarol and diuron to D. tertiolecta cultures under simulated spring and autumn irradiance conditions, thereby providing the first experimental confirmation that seasonal variation in irradiance indeed affects herbicide toxicity to microalgae. Results of previous studies on the toxicity of both Irgarol and diuron to microalgae are recently reviewed by Suresh Kumar et al. (2014). It was found that Irgarol, used in antifouling paints on ship hulls, is highly toxic to individual microalgal species as well as to microalgal communities (e.g., Bérard et al., 2003; Devilla et al., 2005; Gatidou and Thomaidis, 2007; Buma et al., 2009; Sjollema et al., 2014). Negative effects of diuron, used in agriculture and antifouling paints, on individual microalgal species and communities have also been described (e.g., Gatidou and Thomaidis, 2007; Magnusson et al., 2008; Knauert et al., 2009; Pesce et al., 2010; 


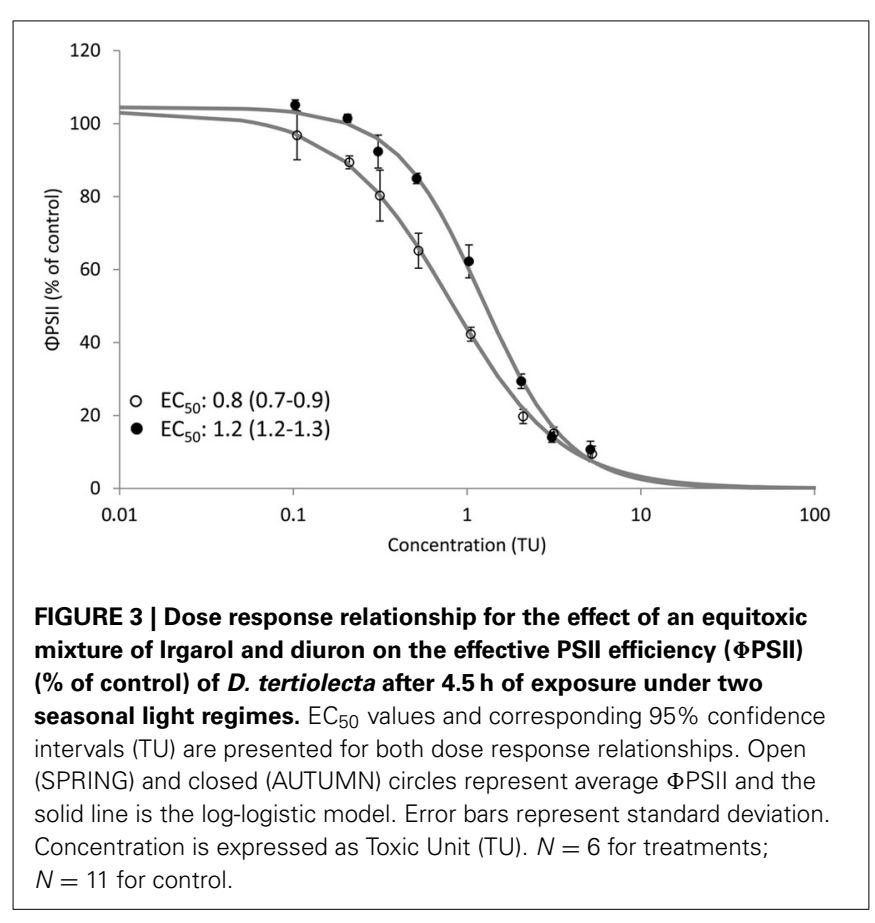

Sjollema et al., 2014). From these studies it can be concluded that Irgarol is in general more toxic to microalgae compared to diuron (Gatidou and Thomaidis, 2007; Sjollema et al., 2014), which was confirmed by the present study. However, the majority of the toxicity tests of Irgarol and diuron are performed under standardized laboratory conditions, using fluorescent tubes as a light source. As the present study demonstrated that irradiance conditions affect the toxicity of these herbicides, the question remains how these reported toxicity levels relate to the actual risk of these compounds under field conditions. The observed short term seasonal-specific effect on ФPSII of these herbicides are indicative for the ecological relevant chronic effect on growth (Magnusson et al., 2008; Buma et al., 2009) and must therefore be taken into account when determining toxic pressure of contaminants in aquatic and marine ecosystems.

Although the differences in toxicity between seasons are relatively small in the present laboratory study, the observations on single herbicides are corroborated by their joint effects under different irradiance regimes. Yet, our observations urge to develop more insight in field relevant irradiance conditions. Algae in the field are exposed to a complex and dynamic light regime with constantly fluctuating light conditions as a result, while this study was performed under constant light conditions, with both seasons based on one solar spectrum measured in spring. Additionally, light intensities will decrease with increasing depth due to absorption and scattering of the light (Kirk, 2011). The main light-absorbing component at wavelength below $500 \mathrm{~nm}$ is chromophoric dissolved organic matter (CDOM or yellow substance/humic mater/Gelbstoff), influencing the ratio between UVA, UVB, total UVR, and PAR (Markager and Vincent, 2000). This reduction in light intensity and changes in contribution of UVA, UVB, total UVR, and PAR in the water will affect the herbicide toxicity to microalgae. As the highest CDOM concentrations are found at locations close to direct sources of terrestrial organic matter (Kowalczuk et al., 2003), it is likely that the phototoxic effects will be location specific. On the other hand, algae can also be present as microphytobenthos on exposed sediments of shallow tidal flats like the Wadden Sea (The Netherlands) where they can be exposed to very high levels of UVR during most of the tidal cycle (Peletier et al., 1996). As a result the photoenhanced toxicity for these benthic species might be higher compared to phytoplankton living in the water column.

Next to the seasonal dynamics in light conditions, concentrations of contaminants can also fluctuate over time. Since diuron is used for agricultural applications and both tested herbicides are used in antifouling products, seasonal fluctuations due to differences in application of these compounds in relation to the growing and boating season are indeed observed (Lamoree et al., 2002). It is likely that peak concentrations coincide with high irradiance levels in spring and summer and consequently microalgae are exposed to higher concentrations of herbicides which also have a higher toxic effect. Additionally, in temperate regions like The Netherlands, the main algal bloom is typically observed in spring (Kaiser et al., 2011), co-occurring with higher contaminant concentrations and high irradiance levels. As a consequence, the hazard and risk for herbicide contamination will be higher during this productive season. Especially in this season, effects on the development of algal populations might potentially affecting higher trophic levels.

The toxic pressure of herbicides in the field will mainly depend on the timing of (1) concentrations of the compounds, (2) presence of algae, and (3) the irradiance spectrum and total light intensity. Additional multi-stress factors which might interfere with the toxicity of the herbicides are nutrient limitation (Hall et al., 1989; Guasch et al., 2004) and temperature (Chalifour and Juneau, 2011). A combination of timing as well as the presence of additional multi-stress factors will determine the herbicide toxicity in the field, while the ultimate effect on the ecosystem will also depend on the ability of the microalgae to recover from damage by solar radiation (Janknegt et al., 2009b) and/or contaminants (Buma et al., 2009; Magnusson et al., 2012). Therefore, standard toxicity test may over- or underestimate the toxic effect when performed under controlled laboratory conditions, thereby misjudging the potential hazard of these compounds in the field.

\section{ACKNOWLEDGMENTS}

This research was financed by DELTARES, The Netherlands. We would like to thank the Technology Centre of the University of Amsterdam (particularly Gerrit Hardeman and Theo van Lieshout) for technical assistance.

\section{REFERENCES}

Bérard, A., Dorigo, U., Mercier, I., Becker-van Slooten, K., Grandjean, D., and Leboulanger, C. (2003). Comparison of the ecotoxicological impact of the triazines Irgarol 1051 and atrazine on microalgal cultures and natural microalgal communities in Lake Geneva. Chemosphere 53, 935-944. doi: 10.1016/S00456535(03)00674-X

Buma, A. G., De Boer, M. K., and Boelen, P. (2001). Depth distributions of DNA damage in Antarctic marine phyto-and bacterioplankton exposed to summertime UV radiation. J. Phycol. 37, 200-208. doi: 10.1016/j.seares.2008. 11.007

Buma, A. G. J., Sjollema, S. B., van de Poll, W. H., Klamer, H.J. C., and Bakker, J. F. (2009). Impact of the antifouling agent Irgarol 1051 on marine phytoplankton species. J. Sea Res. 61, 133-139. doi: 10.1046/j.1529-8817.2001.037002200.x 
Chalifour, A., and Juneau, P. (2011). Temperature-dependent sensitivity of growth and photosynthesis of Scenedesmus obliquus, Navicula pelliculosa and two strains of Microcystis aeruginosa to the herbicide atrazine. Aquat. Toxicol. 103, 9-17. doi: 10.1016/j.aquatox.2011.01.016

Coldiron, B. M. (1992). Thinning of the ozone layer: facts and consequences. J. Am. Acad. Dermatol. 27, 653-662. doi: 10.1016/0190-9622(92)70233-6

Devilla, R. A., Brown, M. T., Donkin, M., Tarran, G. A., Aiken, J., and Readman, J. W. (2005). Impact of antifouling booster biocides on single microalgal species and on a natural marine phytoplankton community. Mar. Ecol. Prog. Ser. 286, 1-12. doi: 10.3354/meps286001

Gala, W. R., and Giesy, J. P. (1992). Photo-induced toxicity of anthracene to the green alga, Selenastrum capricornutum. Arch. Environ. Contam. Toxicol. 23, 316-323. doi: 10.1007/BF00216240

Gatidou, G., and Thomaidis, N. S. (2007). Evaluation of single and joint toxic effects of two antifouling biocides, their main metabolites and copper using phytoplankton bioassays. Aquat. Toxicol. 85, 184-191. doi: 10.1016/j.aquatox. 2007.09.002

Guasch, H., Muñoz, I., Rosés, N., and Sabater, S. (1997). Changes in atrazine toxicity throughout succession of stream periphyton communities. J. Appl. Phycol. 9, 137-146.

Guasch, H., Navarro, E., Serra, A., and Sabater, S. (2004). Phosphate limitation influences the sensitivity to copper in periphytic algae. Freshw. Biol. 49, 463-473. doi: 10.1111/j.1365-2427.2004.01196.x

Guasch, H., and Sabater, S. (1998). Light history influences the sensitivity to atrazine in periphytic algae. J. Phycol. 34, 233-241. doi: 10.1046/j.15298817.1998.340233.x

Guillard, R. R. (1975). "Culture of phytoplankton for feeding marine invertebrates," in Culture of Marine Invertebrate Animals, eds W. L. Smith and M. H. Chanley (New York, NY: Plenum Press), 29-60. doi: 10.1007/978-1-4615-8714-9_3

Haanstra, L., Doelman, P., and Voshaar, J. H. O. (1985). The use of sigmoidal dose response curves in soil ecotoxicological research. Plant Soil 84, 293-297. doi: 10.1007/BF02143194

Hall, J., Healey, F. P., and Robinson, G. G. C. (1989). The interaction of chronic copper toxicity with nutrient limitation in two chlorophytes in batch culture. Aquat. Toxicol. 14, 1-13. doi: 10.1016/0166-445X(89)90051-9

Helbling, E. W., Buma, A. G., de Boer, M. K., and Villafañe, V. E. (2001). In situ impact of solar ultraviolet radiation on photosynthesis and DNA in temperate marine phytoplankton. Mar. Ecol. Prog. Ser. 211, 43-49. doi: $10.3354 /$ meps 211043

Hylland, K., and Vethaak, A. D. (2011). "Impact of contaminants on pelagic ecosystems Chapter 10," in Ecological Impacts of Toxic Chemicals, eds F. Sánchez-Bayo, P. J. van den Brink, and R. M. Mann (Bentham Science Publishers Ltd), 212-224.

Janknegt, P. J., De Graaff, C. M., Van de Poll, W. H., Visser, R. J., Helbling, E. W., and Buma, A. G. J. (2009a). Antioxidative responses of two marine microalgae during acclimation to static and fluctuating natural UV radiation. Photochem. Photobiol. 85, 1336-1345. doi: 10.1111/j.1751-1097.2009.00603.x

Janknegt, P. J., De Graaff, C. M., Van De Poll, W. H., Visser, R. J., Rijstenbil, J. W., and Buma, A. G. J. (2009b). Short-term antioxidative responses of 15 microalgae exposed to excessive irradiance including ultraviolet radiation. Eur. J. Phycol. 44, 525-539. doi: 10.1080/09670260902943273

Kaiser, M. J., Attrill, M. J., Jennings, S., Thomas, D. N., Barnes, D. K. A., Brierley, A. S., et al. (2011). Marine Ecology: Processes, Systems, and Impacts. Oxford: Oxford University Press.

Kirk, J. T. O. (2011). Light and Photosynthesis in Aquatic Ecosystems. New York, NY: Cambridge university press.

Knauert, S., Dawo, U., Hollender, J., Hommen, U., and Knauer, K., (2009). Effects of photosystem II inhibitors and their mixture on freshwater phytoplankton succession in outdoor mesocosms. Environ. Toxicol. Chem. 28, 836-845. doi: 10.1897/08-135R.1

Könemann, H. (1981). Fish toxicity tests with mixtures of more than two chemicals: a proposal for a quantitative approach and experimental results. Toxicology 19, 229-238. doi: 10.1016/0300-483X(81)90132-3

Kowalczuk, P., Cooper, W. J., Whitehead, R. F., Durako, M. J., and Sheldon, W. (2003). Characterization of CDOM in an organic-rich river and surrounding coastal ocean in the South Atlantic Bight. Aquat. Sci. 65, 384-401. doi: 10.1007/s00027-003-0678-1

Lamoree, M. H., Swart, C. P., van der Horst, A., and van Hattum, B. (2002). Determination of diuron and the antifouling paint biocide Irgarol 1051 in Dutch marinas and coastal waters. J. Chromatogr. A 970, 183-190. doi: 10.1016/S0021-9673(02)00878-6
Larson, R. A., and Berenbaum, M. R. (1988). Environmental phototoxicity. Environ. Sci. Technol. 22, 354-360. doi: 10.1021/es00169a001

Lin, Y., Karuppiah, M., Shaw, A., and Gupta, G. (1999). Effect of simulated sunlight on atrazine and metolachlor toxicity of surface waters. Ecotoxicol. Environ. Saf. 43, 35-37. doi: 10.1006/eesa.1998.1751

Magnusson, M., Heimann, K., and Negri, A. P. (2008). Comparative effects of herbicides on photosynthesis and growth of tropical estuarine microalgae. Mar. Pollut. Bull. 56, 1545-1552. doi: 10.1016/j.marpolbul.2008.05.023

Magnusson, M., Heimann, K., Ridd, M., and Negri, A. P. (2012). Chronic herbicide exposures affect the sensitivity and community structure of tropical benthic microalgae. Mar. Pollut. Bull. 65, 363-372. doi: 10.1016/j.marpolbul. 2011.09.029

Markager, S., and Vincent, W. F. (2000). Spectral light attenuation and the absorption of UV and blue light in natural waters. Limnol. Oceanogr. 45, 642-650. doi: 10.4319/lo.2000.45.3.0642

Peletier, H., Gieskes, W. W. C., and Buma, A. G. J. (1996). Ultraviolet-B radiation resistance of benthic diatoms isolated from tidal flats in the Dutch Wadden Sea. Mar. Ecol. Prog. Ser. 135, 163-168. doi: 10.3354/meps135163

Pelletier, É., Sargian, P., Payet, J., and Demers, S. (2006). Ecotoxicological effects of combined UVB and organic contaminants in coastal waters: a review. Photochem. Photobiol. 82, 981-993. doi: 10.1562/2005-09-18-RA-688.1

Pesce, S., Lissalde, S., Lavieille, D., Margoum, C., Mazzella, N., Roubeix, V., et al. (2010). Evaluation of single and joint toxic effects of diuron and its main metabolites on natural phototrophic biofilms using a pollution-induced community tolerance (PICT) approach. Aquat. Toxicol. 99, 492-499. doi: 10.1016/j.aquatox.2010.06.006

Royal Netherlands Meteorological Institute. Measuring station De Kooy. Avilable online at: http://data/knmi.nl (Accessed May, 2013).

Ruben, H. J., Cosper, E. M., and Wurster, C. F. (1990). Influence of light intensity and photoadaptation on the toxicity of PCB to a marine diatom. Environ. Toxicol. Chem. 9, 777-784. doi: 10.1002/etc.5620090612

Sargian, P., Pelletier, E., Mostajir, B., Ferreyra, G. A., and Demers, S. (2005). TBT toxicity on a natural planktonic assemblage exposed to enhanced ultraviolet-B radiation. Aquat. Toxicol. 73, 299-314. doi: 10.1016/j.aquatox.2005.03.019

Sjollema, S. B., MartínezGarcía, G., van der Geest, H. G., Kraak, M. H. S., Booij, P., Vethaak, A. D., et al. (2014). Hazard and risk of herbicides for marine microalgae. Environ. Pollut. 187, 106-111. doi: 10.1016/j.envpol.2013. 12.019

Southerland, H. A., and Lewitus, A. J. (2004). Physiological responses of estuarine phytoplankton to ultraviolet light-induced fluoranthene toxicity. J. Exp. Mar. Biol. Ecol. 298, 303-322. doi: 10.1016/S0022-0981(03)00364-2

Suresh Kumar, K., Dahms, H., Lee, J., Kim, H. C., Lee, W. C., and Shin, K. (2014). Algal photosynthetic responses to toxic metals and herbicides assessed by chlorophyll a fluorescence. Ecotoxicol. Environ. Saf. 104, 51-71. doi: 10.1016/j.ecoenv.2014.01.042

Vassiliev, I. R., Prasil, O., Wyman, K. D., Kolber, Z., Hanson, A. K., Prentice, J. E., et al. (1994). Inhibition of PS II photochemistry by PAR and UV radiation in natural phytoplankton communities. Photosyn. Res. 42, 51-64. doi: 10.1007/BF00019058

Wiegman, S., van Vlaardingen, P. L., Bleeker, E. A., de Voogt, P., and Kraak, M. H. (2001). Phototoxicity of azaarene isomers to the marine flagellate Dunaliella tertiolecta. Environ. Toxicol. Chem. 20, 1544-1550. doi: 10.1002/etc.5620200718

Conflict of Interest Statement: The authors declare that the research was conducted in the absence of any commercial or financial relationships that could be construed as a potential conflict of interest.

Received: 29 January 2014; accepted: 19 May 2014; published online: 04 June 2014. Citation: Sjollema SB, Vavourakis CD, van der Geest HG, Vethaak AD and Admiraal $W$ (2014) Seasonal variability in irradiance affects herbicide toxicity to the marine flagellate Dunaliella tertiolecta. Front. Mar. Sci. 1:13. doi: 10.3389/fmars.2014.00013 This article was submitted to Marine Pollution, a section of the journal Frontiers in Marine Science.

Copyright (c) 2014 Sjollema, Vavourakis, van der Geest, Vethaak and Admiraal. This is an open-access article distributed under the terms of the Creative Commons Attribution License (CC BY). The use, distribution or reproduction in other forums is permitted, provided the original author(s) or licensor are credited and that the original publication in this journal is cited, in accordance with accepted academic practice. No use, distribution or reproduction is permitted which does not comply with these terms. 